\title{
Processing and Properties of Carbon Nanotube PVC Composites
}

\author{
Kristin Trommer, Carina Petzold, and Bernd Morgenstern \\ Research Institute of Leather and Plastic Sheeting (FILK) Freiberg, Meißner Ring 1-5, 09599 Freiberg, Germany \\ Correspondence should be addressed to Kristin Trommer; kristin.trommer@filkfreiberg.de
}

Received 12 May 2014; Accepted 19 July 2014; Published 17 August 2014

Academic Editor: Parsotam H. Parsania

Copyright (C) 2014 Kristin Trommer et al. This is an open access article distributed under the Creative Commons Attribution License, which permits unrestricted use, distribution, and reproduction in any medium, provided the original work is properly cited.

Commercially available multiwalled carbon nanotubes (MWCNT) were incorporated in coating masses based on PVC by means of three roll mill. The best results could be obtained using the $5 \mu \mathrm{m}$ gap. Thin PVC sheets were formed via knife coating having an electrical conductivity up to $1,500 \mathrm{~S} / \mathrm{m}$ that are applicable as electric heating elements. For the use in the antistatic range, CNT contents $\leq 0.5 \%$ are sufficient. Rheological measurements indicate the quality of particle processing. AFM investigations are suitable to investigate the alignment of the nanoparticles in the bulk polymer. Using this method, the decrease of agglomerates as well as the splitting of CNT bundles within further mass processing could be visualized.

\section{Introduction}

Sheets and coatings made of plasticized polyvinyl chloride (PVC-P) are currently applied to a variety of products for various utilizations. In 2010, PVC-P was set to the top of the total production of coated fabrics with a share rate of $48 \%$. This corresponds to approximately 200-230 million $\mathrm{m}^{2}$. Among them there are more than $25 \%$ canvas materials; $10 \%$ to $15 \%$ are products of textile architecture (roof sheeting and waterproofs), advertising goods (banners and billboards), and also tents as well as marquees and sun screens. Further important applications include conveyor belts, floor coverings, inflatable items, and artificial leather for the automotive industry or upholstery in public spaces. Because of the various purposes, the requirements concerning the materials' properties are very different. Depending on the exact field of application, the coated materials are required to have a variety of special properties. These include, for instance, cut and abrasion resistance, flame retardant, heat protection, antistatic or electrical conductivity, and resistances to soiling, dust, gas, UV-radiation, or chemicals. In order to generate such properties, the polymer matrix is provided with additive compounds in liquid or particle form. Prior art is the use of filler materials with particle sizes in the micrometer range. Such particles enable the setting of the desired function. At the same time, they also change polymeric properties such as high mechanical performance (tensile strength, elongation at break, and cold flexibility), ageing, or migration. The use of additive compounds with a particle size distribution in the micrometer range of approximately $20 \mu \mathrm{m}$ especially restricts a thin layer development. Because of the particle sizes, defectfree layers with thicknesses below $60 \mu \mathrm{m}$ are hardly feasible. However, often the desired material properties can be set in a targeted way by using small amounts of nanoparticles. Carbon-based nanoparticles with a high aspect ratio are often applied to reach properties like antistatic or electrical conductivity. Carbon nanotubes (CNT) or graphene is especially suitable. Several publications already described analyses concerning the percolation ranges of these particles in polymers. The review articles $[1,2]$ provide a comprehensive overview. So far, the focus for integration into paste-like polymeric masses was on the combination of nanoparticles with epoxy resins. PVC layers are hardly investigated. In [3, 4] the electrical and the thermal behavior of PVC-MWCNT nanocomposites are analyzed; in $[5,6]$ the influence of the glass transition temperature and the mechanical properties are described.

The present paper shows the development of electrically conductive plasticized PVC layers by incorporation of multiwalled carbon nanotubes (MWCNT) in PVC solutions. The preparation of the nanoparticles is the most challenging part in producing the MWCNT polymeric composites. Technical 
MWCNT show, with having a diameter of 5-30 $\mathrm{nm}$ and a length of $>1 \mu \mathrm{m}$, a very high aspect ratio and they form agglomerates. In order to generate electrically conductive paths in the polymeric material, these agglomerates have to be split and spread homogeneously in the polymeric matrix. In contrast to processing in low viscous media, such as water, the remaining agglomerates cannot be separated from the polymeric mass. Usual processes for the splitting of the agglomerates are sonification as well as calendering [6-13]. The maintenance of the high aspect ratio of the MWCNT is the most important criterion for the selection of the agglomerates. If the shearing forces on the filamentary particles are too high, this may result in a break. In this paper the dependencies between the process conditions during particle preparation and the properties of the pastes as well as the electrical conductivity of the polymeric composite are analyzed. The nanoparticles in the processed mass were characterized by using atomic force microscopy (AFM). This method is increasingly used for the characterization of CNT nanoparticles in polymers because it enables visualizing structures up to the lower nanometer range [14-17].

The preparation of nanoparticle-functionalized electrically conductive plasticized PVC layers is continuously possible from roll to roll, whereas the PVC layer can be formed as flexible textile coating or as separate film.

\section{Materials and Methods}

2.1. Materials. The PVC sheets were prepared of E-PVC EP 7060 (Vinnolit GmbH \& Co. KG) and Hexamoll DINCH (BASF) as plasticizers. KRTTS (titanium triisostearoylisopropoxide, Simagchem Corp.) (additive 1) and Byk 2155 (BYK Chemistry $\mathrm{GmbH}$ ) (additive 2) were used as additives. The properties of the used conductive particles are summarized in Table 1. The particles were used without any further modification.

\subsection{Characterization Methods}

2.2.1. Measurement of the Surface Resistance. According to DIN 54345 part 1, the surface resistance was measured as four-terminal method (Kelvin method) using the measuring device Milli-To2 of Fischer Elektronik $\mathrm{GmbH} \& \mathrm{Co}$. Four-terminal method is an electrical impedance measuring technique that uses separate pairs of current-carrying and voltage-sensing electrodes. The key advantage of fourterminal sensing is that the separation of current and voltage electrodes eliminates the impedance contribution of the wiring and contact resistances. The equipment allows resistivity measurements up to $2 \times 10^{6} \Omega$. After climate conditioning ( $24 \mathrm{~h}, 23^{\circ} \mathrm{C}$, and $50 \%$ rel. humidity), the samples were applied with a voltage of $750 \mathrm{mV}$ for $60 \mathrm{~s}$. The thickness of the samples was $50 \mu \mathrm{m}$ or $100 \mu \mathrm{m}$. Due to the small layer thickness and the low ratio between thickness and electrode distance of less than one of hundreds, the resistivity as well as the electrical conductivity can be calculated from the measuring value of the square resistance by multiplying the thickness.
2.2.2. AFM Measurements. An atomic force microscope of the type Nanowizard 3 of the company JPK Instruments was used for the structure measurements in the nanometer range. The scanning unit of the apparatus is able to detect a grid of up to $100 \times 100 \times 15$ microns ( $X Y Z$ direction). The measurements were performed in tapping mode. For the evaluation, the images of height, amplitude, and phase were used.

2.2.3. Analysis of the Viscosity. The rheological analyses were carried out by using a Modular Compact Rheometer MCR 300 of Anton Paar $\mathrm{GmbH}$ with comprehensive evaluation software. The measuring range of the rheometer comprises a torque range from $0.5 \mu \mathrm{Nm}$ to $120 \mathrm{mNm}$. For measurements, the cone/plate measuring system CP50-1 was used. The flow curves were recorded at $23^{\circ} \mathrm{C}$ within a shear range of $0-$ $1,000 \mathrm{~s}^{-1}$.

\subsection{Preparation of PVC Nanocomposites}

2.3.1. Material Preparation. In order to obtain an optimal dispersion of the CNT, the particles were incorporated into a PVC solution. For this purpose, a 10\% PVC solution was prepared of $180 \mathrm{~g}$ EP 7060 and 1,620 g cyclohexanone during the first step. The solvent was put into a temperature-controlled vessel and under stirring conditions the PVC powder was added. The mixture was stirred for 3 hours at $30^{\circ} \mathrm{C}$ and $1,000 \mathrm{r} / \mathrm{min}$. Afterwards the PVC was completely dissolved. This solution was used as stock solution from which the respective quantities were taken for further processing to CNT-containing masses. Generally $240 \mathrm{~g}$ of the PVC solution $(24 \mathrm{~g}$ PVC $=100 \mathrm{phr})$ was intensely mixed with $50 \mathrm{phr}$ of DINCH (plasticizer), 1.5 phr of process additive Byk 1770 and disperser additive. The ratios refer, respectively, to $100 \mathrm{phr}$ of PVC. The quantity of disperser additives depends on the quantity of CNT. Disperser additives and CNT particles were always used at a proportion of $1: 1$. The CNT particles were added at the end to the homogeneous polymeric solution with ratios of $0.5 \%$ up to $6 \%$ based on the total solid content of the mixture. Furthermore the homogenous dispersion was processed at a three roll mill (120 EH-250 of EXAKT) in several passages. The roll mill consists of two roller gaps which can be operated with a defined roller gap or a defined force that presses the rolls together. Several operation modi were set to optimize the process parameters: gap mode of $10 \mu \mathrm{m}$ (process parameter $\mathrm{O}$ ) and $5 \mu \mathrm{m}$ (process parameter $\mathrm{A}$ ) as well as force mode of $5 \mathrm{~N}$ (process parameter $\mathrm{B}$ ) and $12 \mathrm{~N}$ (process parameter C). For each set of parameters, a part of the mass was separated for characterization and the further processing into coating sheets.

2.3.2. Preparation of PVC Sheets. From the prepared PVC masses, CNT films were prepared with a thickness of $50 \mu \mathrm{m}$ and $100 \mu \mathrm{m}$ by blade coating. For that the compounds were spread out on release paper at a Mathis Labcoater in order to form thin layers which were dried for 3 minutes at $100^{\circ} \mathrm{C}$ and cured for 5 minutes at $160^{\circ} \mathrm{C}$. Afterwards the cured layers were delaminated from the release paper to become a thin film of 
TABle 1: Properties of the different particles (manufacturer data).

\begin{tabular}{lcccc}
\hline Product & Nanocyl & Baytubes & WM-CNT & Acetylene black P50 uv \\
\hline Manufacturer & NC 7000 & C150P & CP-0017-SG & SKW Stickstoffwerke \\
Panocyl SA & Bayer material science & $\begin{array}{c}\text { IoLiTec ionic liquids } \\
\text { technologies GmbH }\end{array}$ & D \\
Indication & CNT-A & AG & CNT-C & $99.5 \%$ \\
Carbon purity & $90 \%$ & CNT-B & $95 \%$ & Not specified \\
Diameter & $9.5 \mathrm{~nm}$ & $95 \%$ & $11-20 \mathrm{~nm}$ & Not specified \\
Length & $1.5 \mu \mathrm{m}$ & $4-13 \mathrm{~nm}$ & $5-15 \mu \mathrm{m}$ & $70 \mathrm{~m}^{2} / \mathrm{g}$ \\
Surface area & $250-300 \mathrm{~m}^{2} / \mathrm{g}$ & $1 \mu \mathrm{m}$ & $40-300 \mathrm{~m}^{2} / \mathrm{g}$ & $1,900 \mathrm{~kg} / \mathrm{m}^{3}$ \\
Bulk density & $66 \mathrm{~kg} / \mathrm{m}^{3}$ & Not specified & Not specified & $120-150 \mathrm{~kg} / \mathrm{m}^{3}$ \\
\hline
\end{tabular}

$50 \mu \mathrm{m}$ or $100 \mu \mathrm{m}$. These sheets were characterized by using the described methods.

2.3.3. Rheology. The rheological behavior of dispersions with nanoparticles was analyzed within a shear range of $10^{-3}-10^{3} \mathrm{~s}^{-1}$. All samples were equivalent in composition of the polymeric solution in which the nanoparticles were dispersed. Only the type of disperser additive was varied. Samples with a particle content of $1-6 \mathrm{ma} \%$ CNT based on the total solid content were characterized. As expected, the viscosity rises with increasing particle content. The mass shows a structural viscous behavior, if the particle agglomerates were processed into smaller fibrous structures. If this process is not successful and if there are still spherical particles, the dispersions show a nearly Newtonian behavior. In these cases, the flow curves of the PVC solution modified with CNT run parallel to the curve of the pure PVC solution. Figure 1 shows this fact using the example of the CNT-B particles. On Figure 1(a), the flow curves of differently processed CNT dispersions containing 3\% (Newtonian behavior) as well as $4 \%$ (structural viscous behavior) of CNT-B filler material are shown. The light microscopic images (Figure 1(b)) show that the masses with Newtonian behavior contain spherical particle agglomerates, whereas the intrinsically viscous masses contain fibrous particles with a high aspect ratio. Obviously the processing conditions were only suitable for the masses with $4 \%$ CNT-B in order to achieve the desired structures. So the flow curve delivers the first information whether the particle processing into smaller structures with high aspect ratio was successful.

\section{Results and Discussion}

3.1. Characterization of the Paste-Like Coating Compound. The splitting of the CNT-C particles into fibrous structures cannot be achieved in any test with the applied process method on the three roll mill. All compounds filled with CNT-C particles showed Newtonian flow behavior and the light microscopic images were similar to those shown in Figure 1(b) bottom. Contrary to the CNT-C particles, the CNT-A particles could always be split into fibrous structures by treating on the three roll mill. According to the processing steps $\mathrm{O}, \mathrm{A}$ (gap mode) and $\mathrm{B}, \mathrm{C}$ (force mode), each of these compounds was comprehensively characterized in rheological terms. For all flow curves, the particle contents of the compounds prepared in gap mode differ only slightly. The same applies for a CNT content of up to $4 \%$ also for processing in force mode. During transition from gap mode to force mode, a significant increase in viscosity is observed. For a particle content of more than $5 \%$, viscosity of the compound processed at a lower force (B) differs from that of the compound processed at high force (C). The flow curve (B) runs between the curves resulting from gap processing $(\mathrm{O}, \mathrm{A})$ and force processing $\mathrm{C}$. For compounds which were processed in force mode $\mathrm{C}$, viscosity in the shear range between $1 \mathrm{~s}^{-1}$ and $1000 \mathrm{~s}^{-1}$ increases by about one power of ten (Figure 2). With a shear rate of $1 \mathrm{~s}^{-1}$, the viscosity of the compounds processed in gap mode under the condition $\mathrm{O}$ also differs from that processed in force mode, condition $\mathrm{C}$, up to one power of ten. In order to achieve such an effect, much more particles have to be created in force mode than in gap mode. This can be caused either by improving the separation or by breaking the CNT.

The higher the particle quantity is, the steeper the flow curve is. For processing films and coatings, a shear range between $50 \mathrm{~s}^{-1}$ and $1000 \mathrm{~s}^{-1}$ is important. The measured viscosity below 10 Pas enables an application by using the blade coating process.

The further characterization of the compounds as well as the sheets produced from them concerning electrical conductivity and particle distribution showed that the processing method A is the most suitable. Rheological analyses over 8 weeks showed that the long-term stability for all investigated concentrations is given. For this purpose, the flow curves of the compounds were analyzed after one, seven, and fourteen days, as well as after four and eight weeks. Over this period of time the flow curves are nearly identical. Segregation or sedimentation of the particles could not be observed.

3.1.1. Particle Size and Alignment. In order to get an overview of the distribution behavior of the particles within the matrix and of their composition with regard to their size and form, the polymeric dispersions were examined by light microscopy (LIMI). Figure 3 shows the LIMI images for a PVC compound containing 3\% CNT-A after the processing stages $\mathrm{O}, \mathrm{A}, \mathrm{B}$, and $\mathrm{C}$. 


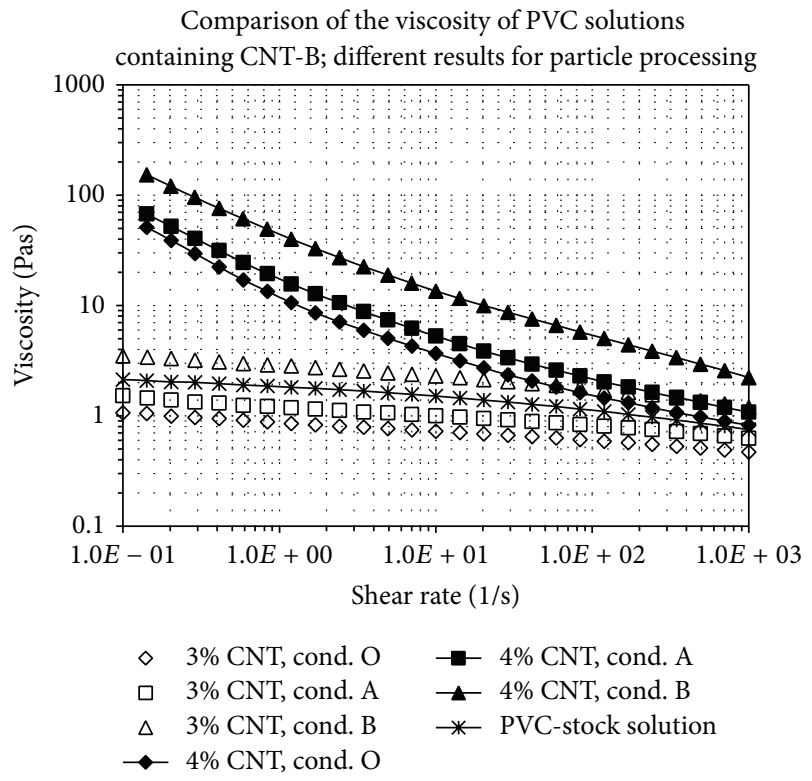

(a)
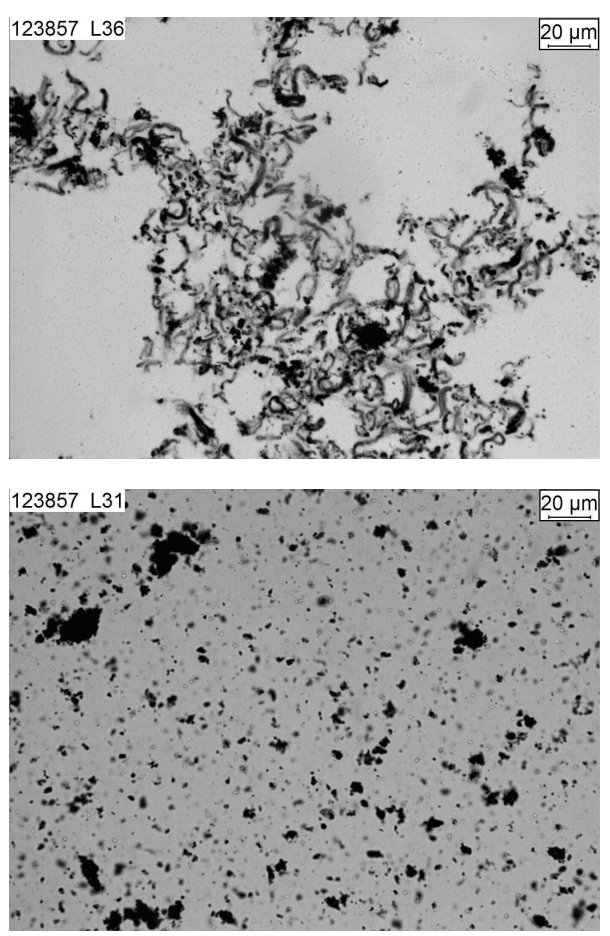

(b)

FIgURE 1: (a) Rheological behavior of CNT-containing PVC solutions which contain particles with high (4\% CNT) and low (3\% CNT) aspect ratio. (b) LIMI images of the CNT-containing dispersions; top with 4\% CNT-B; bottom with 3\% CNT-B.

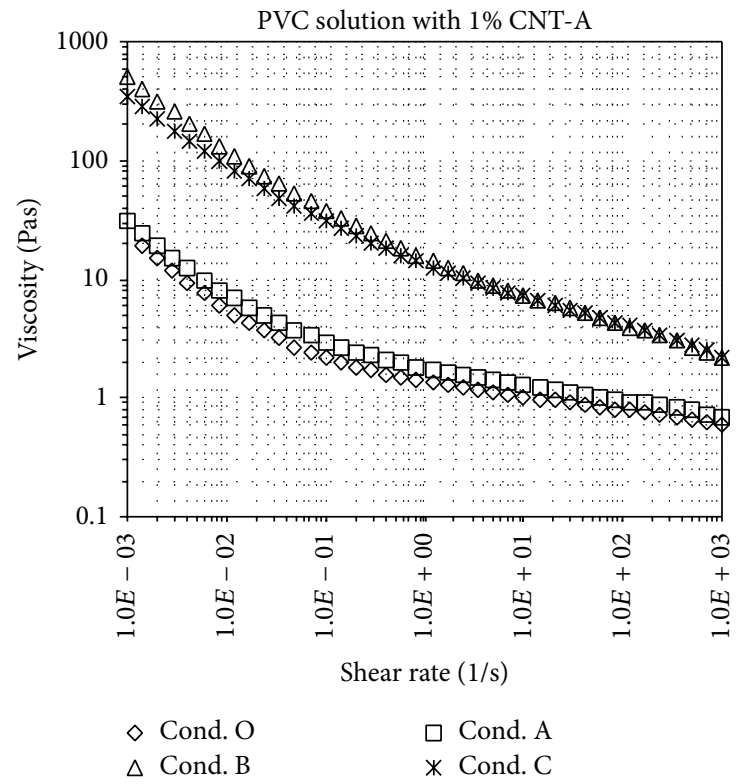

(a)

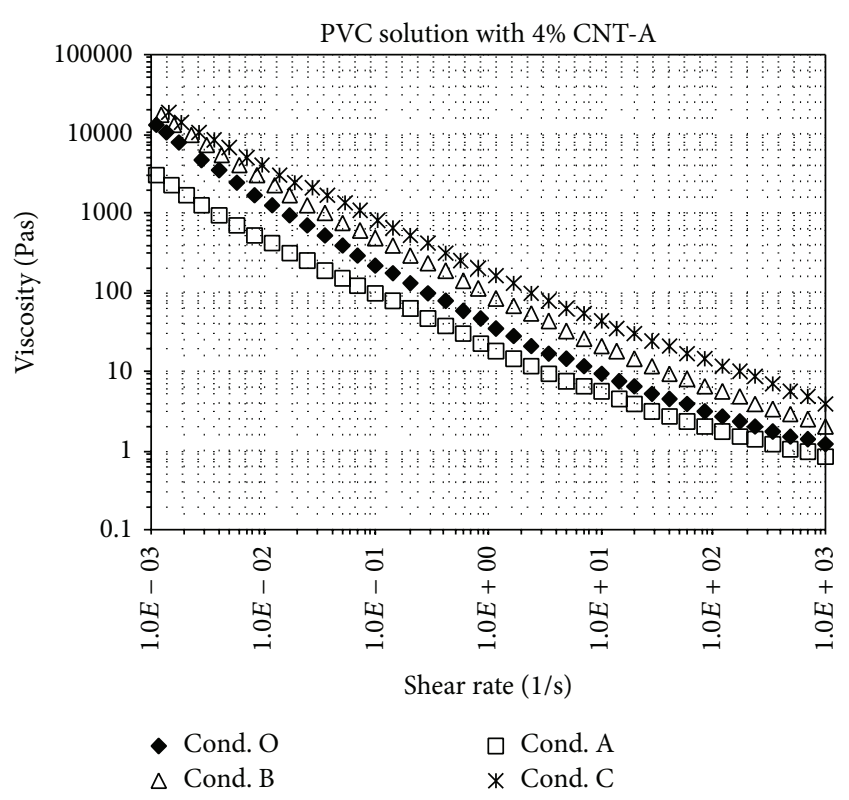

(b)

FIGURE 2: Rheological behavior of PVC solutions with different CNT contents according to different manufacturing processes.

As expected, the particle agglomerates get smaller with diminished roller gap through which the samples are calendered. In the gap mode, this can be set to a minimum of $5 \mu \mathrm{m}$. In force mode, the gap can be smaller. A network of conductive structures is formed after processing the compounds in gap mode $\mathrm{O}$ and $\mathrm{A}$. However, the conductive structures are still rough. In addition to the fibrous structures, there are spherical agglomerates as well. Furthermore, sections with a size range between $10 \mu \mathrm{m}$ and $20 \mu \mathrm{m}$ can be seen where no conductive particles exist. Transition from gap to force 
mode entails a clear change in the compound. The structures are much smaller and seem to be more evenly distributed in the polymer matrix. If the process takes place in force mode, the significant change in the polymeric compound correlates to the effects found in the rheological behavior. For these samples, the resolution achievable with LIMI is not sufficient anymore to analyze the structures. There is no information whether the CNT are better separated or split up already. For clarifying the CNT structures in the polymeric compounds, AFM analyses were consulted with evaluation of the three analysis modes: height, amplitude, and phase. By analogy with the LIMI images, the polymeric compounds were brought to a glass slide and the CNT structures were analyzed.

Figure 4 shows the height, amplitude, and phase images of a PVC compound with CNT-A each after the processes $\mathrm{A}, \mathrm{B}$, and $\mathrm{C}$. The height image clearly shows a decrease of the particulate structures from $\mathrm{A}$ via $\mathrm{B}$ to $\mathrm{C}$. The dimensions of the particles can be determined from the shown section of $40 \times 40 \mu \mathrm{m}$. They measure $7.6 \mu \mathrm{m}$ (STw 0.89 ) for process step A (gap mode), $5.7 \mu \mathrm{m}$ (STw 0.52) for process step B, and only $2.65 \mu \mathrm{m}$ (STw 0.28 ) for process step C. The amplitude and phase images measure $10 \times 10 \mu \mathrm{m}$. The amplitude image shows elongated structures. In combination with the phase image, these structures can be clearly assigned to CNT bundles or matrix effects. After process step A, there are CNT bundles spreading to all sides of the polymeric matrix emanating from the CNT agglomerate. It must be taken into consideration that the agglomerates of the polymeric compounds are isolated due to samples preparation for the AFM images. The CNT structures in the gelled, compact PVC layers are closer to each other. Therefore an intensive interaction of the CNT bundles can be assumed. The diameter of the CNT structures starting from the agglomerates and aligning into the polymeric matrix measures $180 \mathrm{~nm}$ on average. The structures show a length of up to $4 \mu \mathrm{m}$. These values suggest that CNT bundles were separated from the agglomerates, which consist of 10 to 15 nanotubes. The fiber bundles were measured on the basis of a $5 \times 5 \mu \mathrm{m}$ section in the height image (Figure 5). The structures do not present surface effects of the matrix, but they consist of different materials, as shown in the phase image, so that these fibrous structures can be assigned to the CNT.

The AFM images demonstrate that by applying a processing method with a gap of $5 \mu \mathrm{m}$ (process A) CNT bundles can be separated from the agglomerates and aligned. A splitting into primary CNT is not achieved by this way. Also, still larger agglomerates occur in the matrix.

The same applies to the force mode (processes B and C). The agglomerates are further separated, even though the application of force at the roller gap causes a break of the CNT into small fibrous segments. The AFM images in Figure 4 for process $\mathrm{B}$ and $\mathrm{C}$ show entangled $\mathrm{CNT}$ in the area of small agglomerates as well as between the CNT fragments. Longer CNT bundles were not detected anymore. This results in the conclusion that particle processing should ideally be conducted with a small gap and minimum force input. If the force is limited to $<0.4 \mathrm{~N}$, no damage of the CNT was observed.
TABLE 2: Process parameters for compound preparation at the threeroll mill.

\begin{tabular}{lcc}
\hline Designation & Gap 1 & Gap 2 \\
\hline G15 + G10 & Gap: $15 \mu \mathrm{m}$ & Gap: $10 \mu \mathrm{m}$ \\
G10 + G5 & Gap: $10 \mu \mathrm{m}$ & Gap: $5 \mu \mathrm{m}$ \\
G5 + G5 & Gap: $5 \mu \mathrm{m}$ & Gap: $5 \mu \mathrm{m}$ \\
G5 + F1 & Gap: $5 \mu \mathrm{m}$ & Force: $1 \mathrm{~N}$ \\
F3 + F5 & Force: $3 \mathrm{~N}$ & Force: $5 \mathrm{~N}$ \\
F10 + F15 & Force: $10 \mathrm{~N}$ & Force: $15 \mathrm{~N}$ \\
\hline
\end{tabular}

3.2. Electrical Conductivity of PVC Nanocomposites Films. From the PVC compound containing nanoparticles, films of two different thicknesses ( $50 \mu \mathrm{m}$ and $100 \mu \mathrm{m})$ were produced using the blade coating process. The surface resistance of these layers was determined according to DIN 54345 and used as value for the quality of incorporating the nanoparticles. The lower the surface resistance, the more favorable the distribution of the particles in the matrix. The surface resistance of those samples with the same layer thickness can be compared directly. For comparing samples with a different thickness the surface resistance was converted into the resistivity taking into account the thickness (1). From this again the electrical conductivity can be calculated (2)

$$
\begin{aligned}
& \rho=R \times d, \quad \rho \text { resistivity, } d \text { thickness } \\
& \sigma=\frac{1}{\rho}, \quad \sigma \text { electrical conductivity. }
\end{aligned}
$$

In order to investigate the influence of process parameters in material preparation on the film properties, films were prepared from the coating composition of each passage on the three roll mill and determined the surface resistance. The process parameters are given in Table 2.

The results for the resistivity show already low values for the first processing step. As expected, the resistivity declines with decreasing gap setting. In principle, the curve progression is similar for all analyzed films. The minimum adjustable gap mode is $5 \mu \mathrm{m}$. As long as the roller gab is defined, the resistivity is reduced. Shifting to force mode processing, an increase of the resistivity is caused. This behavior is demonstrated by Figure 6 showing the measuring values for PVC masses containing 3\% and 4\% CNT-A. In both cases, the resistivity increases during transition to force mode. Processing with a gap of $5 \mu \mathrm{m}$ was determined as optimum. Therefore all coating compositions that differ in formulation but should be compared were prepared by this way. With a filler content of 3\% CNT-A using this processing method a resistivity of $10^{-2} \Omega \mathrm{m}$ and with $4 \%$ CNT-A a resistivity of $5 \times 10^{3} \Omega \mathrm{m}$ could be achieved. The diagrams in Figure 6 show that the values of the resistivity calculated from the surface resistance of films with a thickness of $50 \mu \mathrm{m}$ (light column) and $100 \mu \mathrm{m}$ (dark column) correlate well.

Figure 7(a) shows the percolation graph for the particles CNT-A between $0 \%$ and $6 \%$ in the PVC film. The diagram shows that the resistivity is reduced already with a particle content of $0.5 \%$ from $10^{8} \Omega \mathrm{m}$ (unfilled PVC sheet) down to $10 \Omega \mathrm{m}$. For a content of $1 \%$ CNT-A, the resistivity is 
100-fold magnification
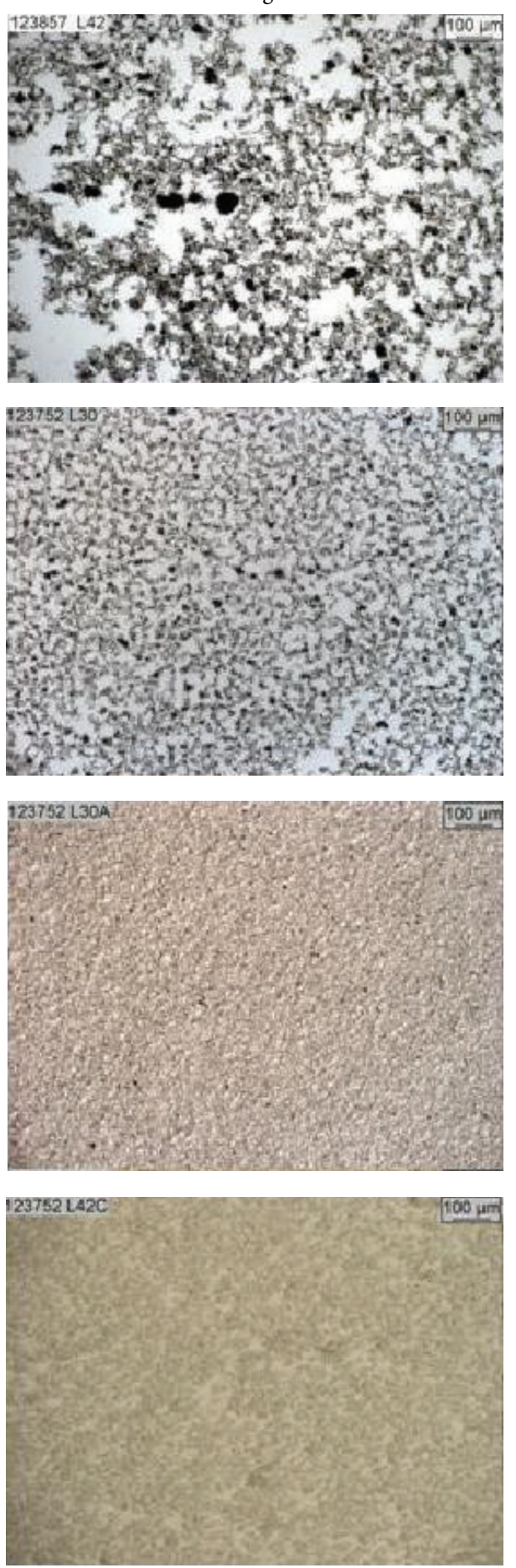

500-fold magnification
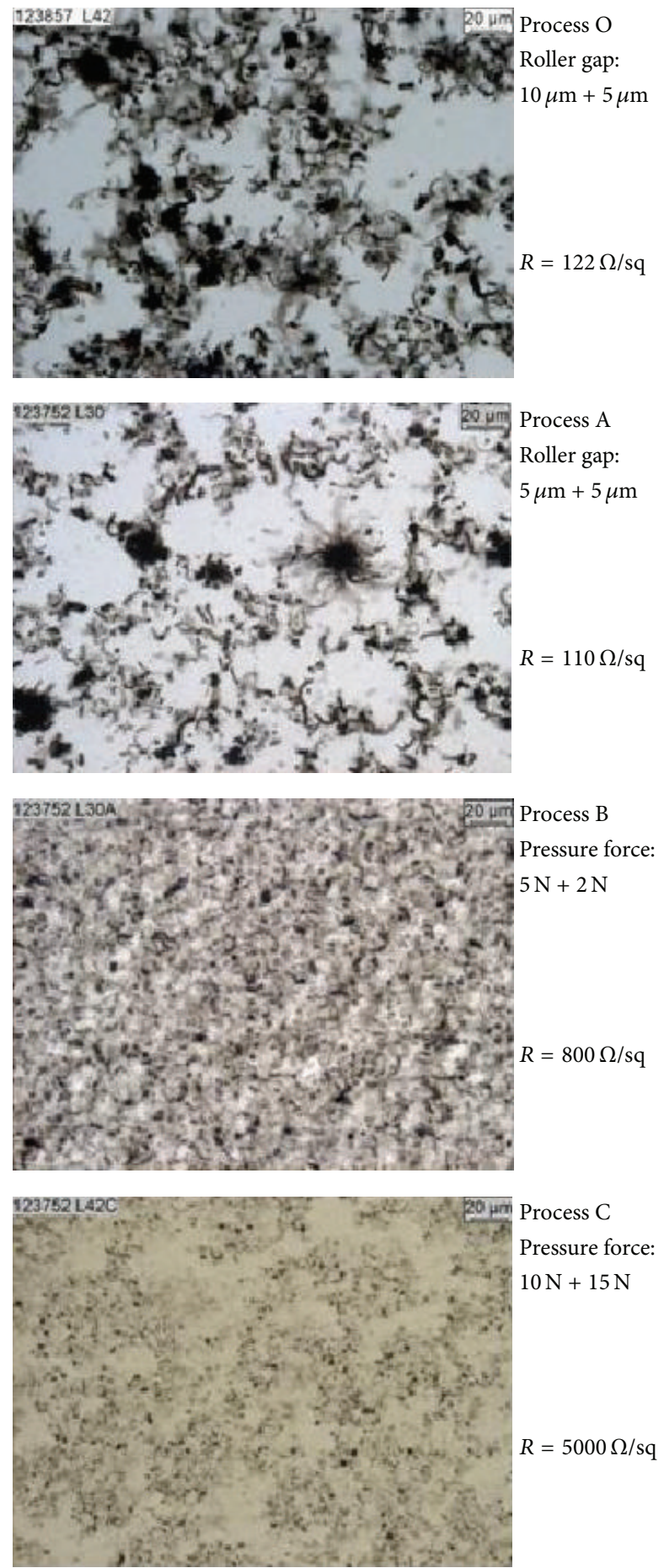

FIGURE 3: LIMI images of differently processed PVC compounds containing 3\% CNT-A ( $R=$ surface resistance).

decreased further to $1 \Omega \mathrm{m}$. For up to $3 \%$ particle content, further adding of one percent CNT-A, respectively, causes a further reduction of the resistivity by about one power of ten. Films containing 3\% of CNT-A show a resistivity of $10^{-2} \Omega \mathrm{m}$. If the CNT content is increased to $6 \%$, the resistivity reduces to $2 \times 10^{-3} \Omega \mathrm{m}$. This corresponds to an electrical conductivity of $480 \mathrm{~S} / \mathrm{m}$. The compounds were prepared with titanate-based (additive 1) and silane-based additive (additive 2) and without dispersing additive. Differences in the resulting electrical properties were only determined for 

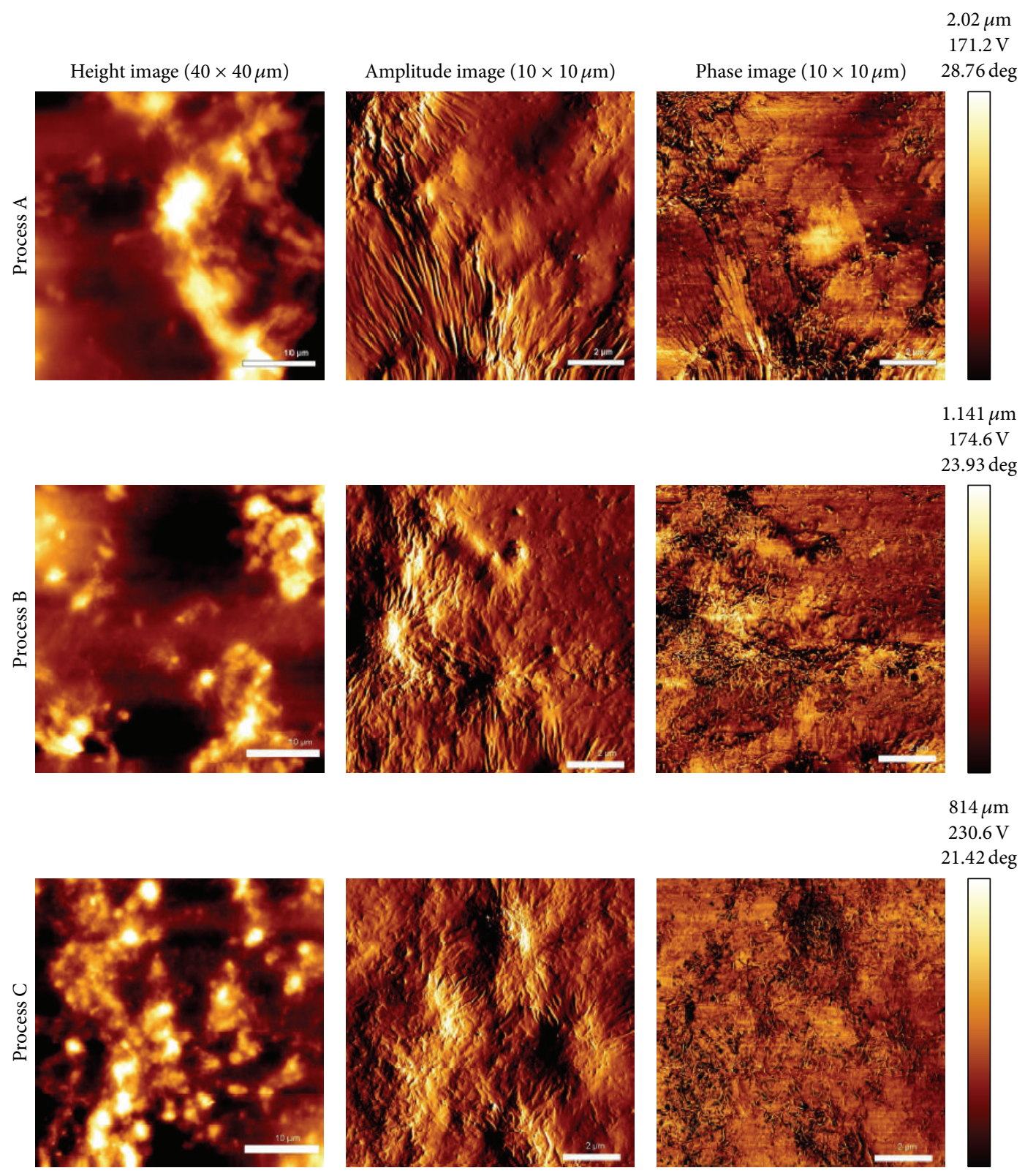

Figure 4: AFM images of PVC compounds containing CNT-A.

particle contents $\leq 2 \%$ (Figure $7(\mathrm{~b})$ ). The films containing the particles CNT-A without additive have the lowest values for the resistivity although the differences are rather small.

By combining CNT-A and particles with particle sizes in the micrometer range (particle D), a synergistic effect was achieved. The interaction of both particle types in the matrix causes a clear reduction of the resistivity. Different mass contents were set, and the effect on the resistance was analyzed. The result is shown in Figure 8. 2\% and 5\% carbon black (D) were added to a coating composition of 3\% CNT-A. The resistivity of the sheets entailed a reduction from about $11 \times 10^{-3} \Omega \mathrm{m}(3 \% \mathrm{CNT}-\mathrm{A})$ to $6.4 \times 10^{-3} \Omega \mathrm{m}(3 \% \mathrm{CNT}-\mathrm{A}$ $+2 \% \mathrm{D})$ or to $3.3 \times 10^{-3} \Omega \mathrm{m}(3 \% \mathrm{CNT}-\mathrm{A}+5 \% \mathrm{D})$. The latter roughly corresponds to the value which is also achieved with 5\% CNT-A. In this case, $2 \%$ CNT can be replaced by $5 \%$ conductive carbon black. Adding $5 \%$ of conductive carbon black to a polymeric matrix containing 6\% CNT-A reduced the resistivity from about $2 \times 10^{-3} \Omega \mathrm{m}(6 \% \mathrm{CNT}$ A) to $6.6 \times 10^{-4} \Omega \mathrm{m}(6 \% \mathrm{CNT}-\mathrm{A}+5 \% \mathrm{D})$. This corresponds to an electrical conductivity of about $1,500 \mathrm{~S} / \mathrm{m}$. Compared to this, a film containing only $5 \%$ of conductive carbon black and no CNT particles has a high resistivity of about $0.445 \Omega \mathrm{m}$ (white column in Figure 8). The described effect could only be achieved with microparticles. Adding flaky nanoparticles only caused a reduction of the resistivity at a similar extent as by adding CNT-A. A synergistic effect can be achieved with the conductive carbon black; however, it was not found. The synergistic effect of CNT and microparticles was also 


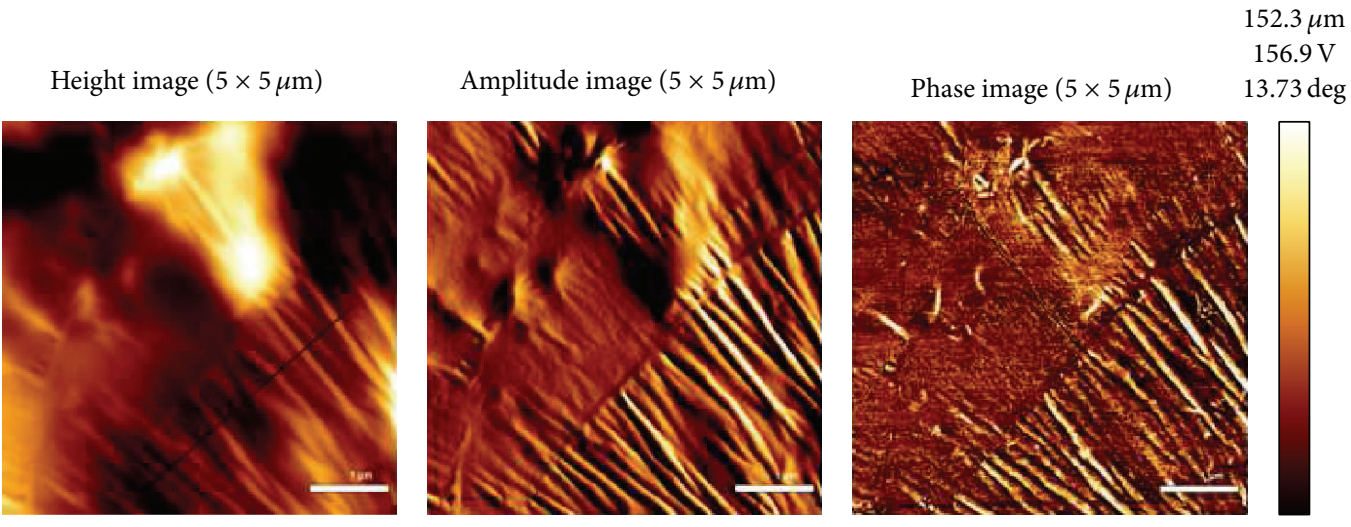

FIGURE 5: AFM images of PVC compound containing CNT-A; the cross section of the fibrous structures was determined along the black line in the amplitude image.

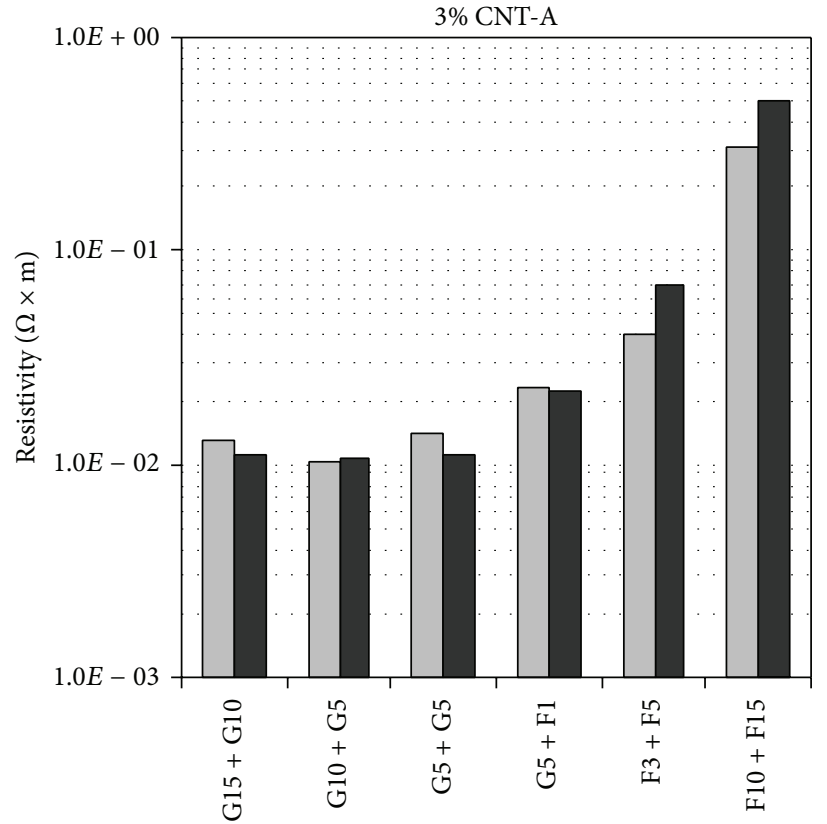

Process conditions

$50 \mu \mathrm{m}$ thickness

$100 \mu \mathrm{m}$ thickness

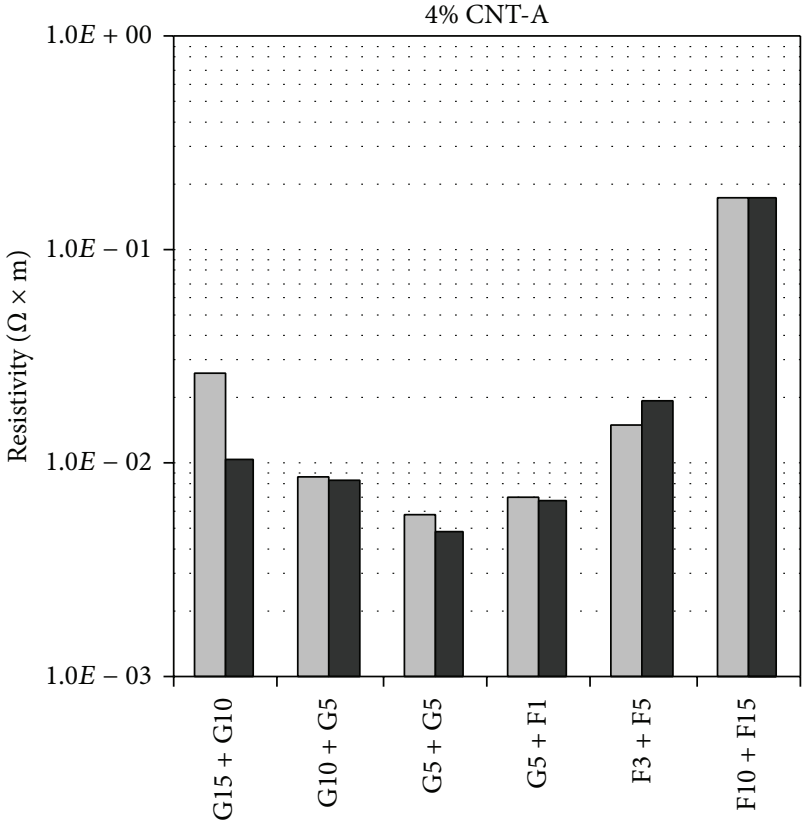

Process conditions

$50 \mu \mathrm{m}$ thickness

$100 \mu \mathrm{m}$ thickness

(a)

(b)

FIGURE 6: Resistivity of PVC films containing 3\% (a) and 4\% (b) CNT-A processed under various conditions; G-gap mode; F-force mode (see Table 2).

observed in other polymers and is described as, for example, epoxy, high density polyethylene, and polyamide 12 [18-20].

\section{Conclusions}

Electrically conductive PVC films could be prepared by incorporating carbon nanotubes into the PVC solutions. The investigation showed that the preparation at the three-roll mill is suitable to split the CNT agglomerates into fibrous structures with a high aspect ratio.
For a first assessment, whether elongated structures were achieved, assessment of the flow curve is suitable. A structural viscous behavior is an indicator for the existence of such structures. Preparing of the compounds in gap mode with a minimum gap of $\leq 5 \mu \mathrm{m}$ is considered to be the optimum. It could be shown that the long, fibrous CNT structures break into short pieces during processing in force mode. As a consequence the viscosity of the masses drastically increases and the films produced of that show a high resistivity. The atomic force microscopy (AFM) is suitable to visualize the 


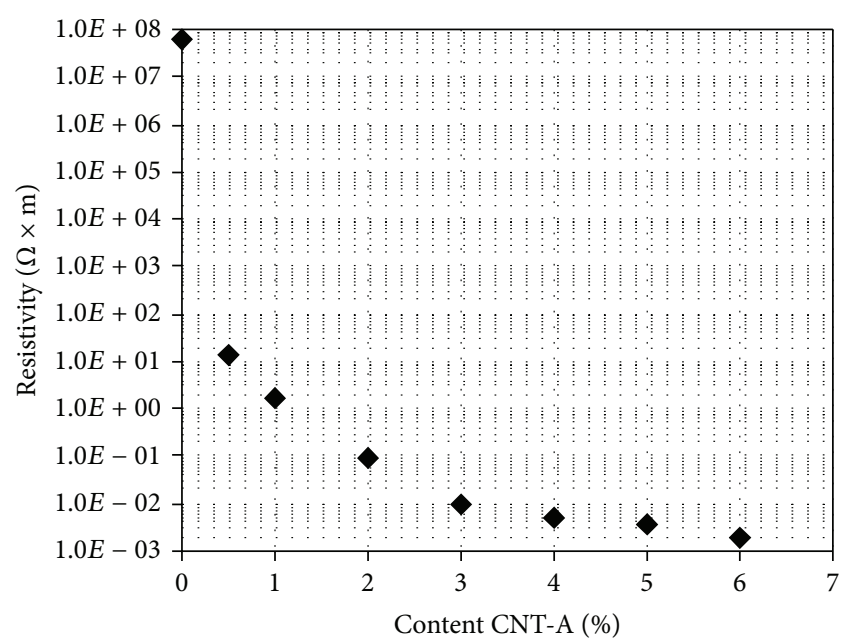

(a)

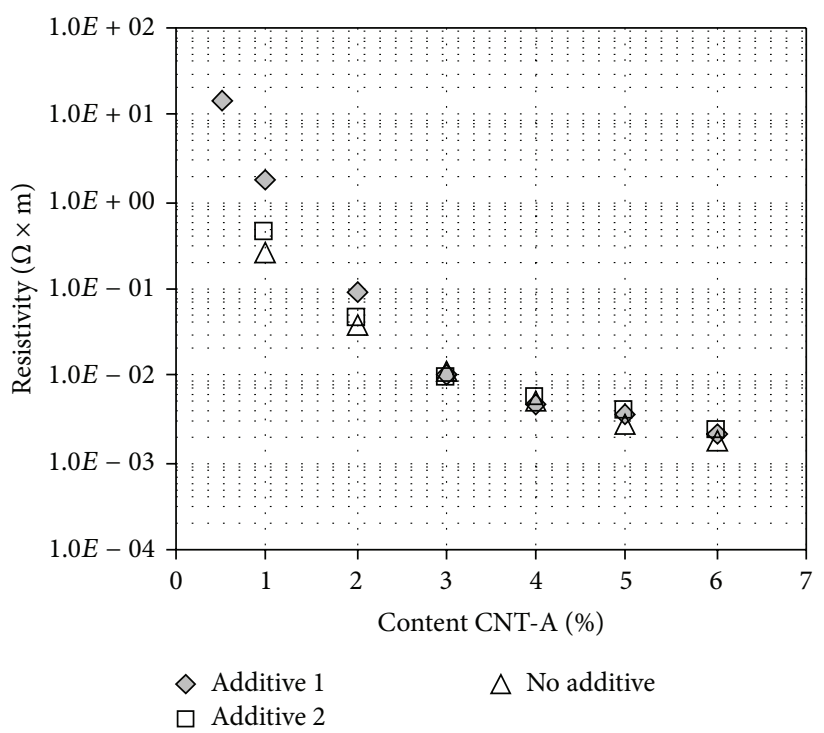

(b)

FIgURE 7: Resistivity of PVC sheets containing up to 6\% CNT-A; (a) CNT-A in PVC containing additive 1 and (b) CNT-A in PVC various additives.

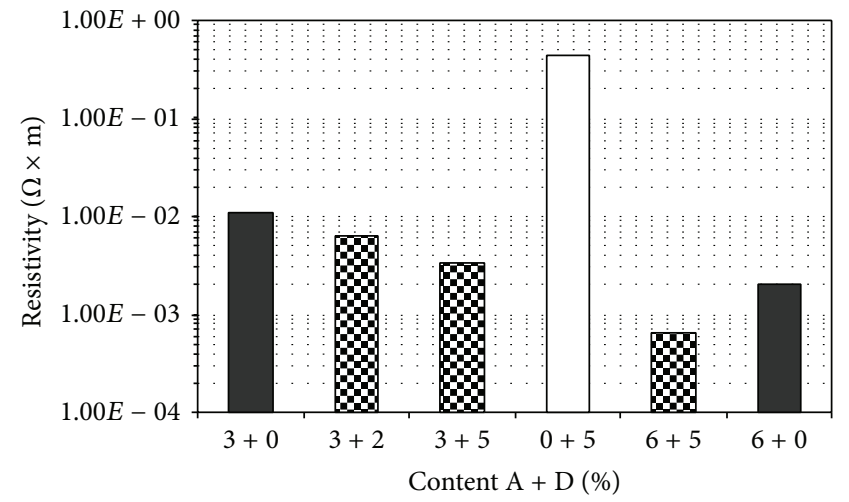

FIGURE 8: Resistivity of PVC films containing CNT (black), acetylene black (white), and both CNT and acetylene black (checked).

arrangement and the size of the particles in the processed compounds.

Optimally treated compounds show a storage stability of at least two months which makes production and storage independently from usage.

Compound processing in gap mode using the particles CNT-A thin PVC sheets could be prepared, achieving an electrical conductivity of up to $480 \mathrm{~S} / \mathrm{m}$. Synergistic effects are obtained by adding conductive carbon black with particle sizes in the micrometer range. An electrical conductivity of $1,500 \mathrm{~S} / \mathrm{m}$ was measured for the combination of $6 \%$ CNTA and $5 \%$ conductive carbon black. This conductivity is sufficient to use these films as electric heating element after suitable contacting, for example, electrically heatable layer in PVC artificial leather or in textile laminates. The conductive PVC layer can be applied as a coat in a multilayer structure as well as separate film useable for laminating processes.
By adding conductive carbon black, the proportion of CNT particles can be optimized and thus the costs can be reduced. For the use in the antistatic range, CNT contents $\leq 0.5 \%$ are sufficient.

\section{Conflict of Interests}

The authors declare that there is no conflict of interests regarding the publication of this paper.

\section{Acknowledgment}

The research project "Modification of plasticized PVC with functional nanoparticles," reg. no. VF110026 was partially promoted from budget funds of the Bundesministerium für Wirtschaft und Technologie (BMWi-Federal Ministry of Economics and Technology). The authors would like to thank the support awarded.

\section{References}

[1] Z. Spitalsky, D. Tasis, K. Papagelis, and C. Galiotis, "Carbon nanotube-polymer composites: chemistry, processing, mechanical and electrical properties," Progress in Polymer Science, vol. 35, no. 3, pp. 357-401, 2010.

[2] W. Bauhofer and J. Z. Kovacs, "A review and analysis of electrical percolation in carbon nanotube polymer composites," Composites Science and Technology, vol. 69, no. 10, pp. 14861498, 2009.

[3] Y. Mamunya, A. Boudenne, N. Lebovka, L. Ibos, Y. Candau, and M. Lisunova, "Electrical and thermophysical behaviour of PVCMWCNT nanocomposites," Composites Science and Technology, vol. 68, no. 9, pp. 1981-1988, 2008.

[4] G. Broza, K. Piszczek, K. Schulte, and T. Sterzynski, "Nanocomposites of poly(vinyl chloride) with carbon nanotubes (CNT)," 
Composites Science and Technology, vol. 67, no. 5, pp. 890-894, 2007.

[5] T. Sterzyński, J. Tomaszewska, K. Piszczek, and K. Skórczewska, "The influence of carbon nanotubes on the PVC glass transition temperature," Composites Science and Technology, vol. 70, no. 6, pp. 966-969, 2010.

[6] J.-H. Shi, B. Yang, K. P. Pramoda, and S. H. Goh, "Enhancement of the mechanical performance of poly(vinyl chloride) using poly(n-butyl methacrylate)-grafted multi-walled carbon nanotubes," Nanotechnology, vol. 18, no. 37, Article ID 375704, 2007.

[7] B. P. Möller, Herstellung, Charakterisierung und Weiterverarbeitung von Carbon Nanotube Dispersionen [Dissertation], Würzburg, Germany, 2013.

[8] J. Z. Kovacs, K. Andresen, J. R. Pauls et al., "Analyzing the quality of carbon nanotube dispersions in polymers using scanning electron microscopy," Carbon, vol. 45, no. 6, pp. 1279-1288, 2007.

[9] J. Z. Kovacs, B. S. Velagala, K. Schulte, and W. Bauhofer, "Two percolation thresholds in carbon nanotube epoxy composites," Composites Science and Technology, vol. 67, no. 5, pp. 922-928, 2007.

[10] F. H. Gojny, M. H. G. Wichmann, U. Köpke, B. Fiedler, and K. Schulte, "Carbon nanotube-reinforced epoxy-composites: enhanced stiffness and fracture toughness at low nanotube content," Composites Science and Technology, vol. 64, no. 15, pp. 2363-2371, 2004.

[11] N. Starostina, M. Brodsky, S. Prikhodko, C. M. Hoo, M. L. Mecartney, and P. West, "AFM capabilities in characterization of particles and surfaces: from angstroms to microns," Pacific Nanotechnology, vol. 59, no. 3, pp. 225-232, 2008.

[12] J. O. Aguilar, J. R. Bautista-Quijano, and F. Avilés, "Influence of carbon nanotube clustering on the electrical conductivity of polymer composite films," Express Polymer Letters, vol. 4, no. 5, pp. 292-299, 2010.

[13] P. Pötschke, A. R. Bhattacharyya, A. Janke et al., "Melt mixing as method to disperse carbon nanotubes into thermoplastic polymers," Fullerenes Nanotubes and Carbon Nanostructures, vol. 13, no. supplement 1, pp. 211-224, 2005.

[14] P. Pötschke, A. R. Bhattacharyya, and A. Janke, "Advanced Multifunctional Nanocarbon Materials and Nanosystems Carbon nanotube-filled polycarbonate composites produced by melt mixing and their use in blends with polyethylene," European Polymer Journal, vol. 40, pp. 137-148, 2004.

[15] J. S. Bunch, T. N. Rhodin, and P. L. McEuen, "NoncontactAFM imaging of molecular surfaces using single-wall carbon nanotube technology," Nanotechnology, vol. 15, no. 2, pp. S76S78, 2004.

[16] A. U. Yalovenko, "AFM investigation of carbon nanotubes," in Proceedings of the SPM 2003, 02.-05.03, pp. 171-173, Nizhny Novgorod, Russia, 2003.

[17] K. Safarova, A. Dvorak, R. Kubinek, M. Vujtek, and A. Rek, "Usage of AFM, SEM and TEM for the research of carbon nanotubes," in Modern Research and Educational Topics in Microscopy, A. Mendéz-Vilas and J. Díaz, Eds., vol. 2, pp. 513519, FORMATEX Microscopy Books, 2007.

[18] R. Socher, B. Krause, S. Hermasch, R. Wursche, and P. Pötschke, "Electrical and thermal properties of polyamide 12 composites with hybrid fillers systems of multiwalled carbon nanotubes and carbon black," Composites Science and Technology, vol. 71, no. 8, pp. 1053-1059, 2011.

[19] J.-H. Lee, S. K. Kim, and N. H. Kim, "Effects of the addition of multi-walled carbon nanotubes on the positive temperature coefficient characteristics of carbon-black-filled high-density polyethylene nanocomposites," Scripta Materialia, vol. 55, no. 12, pp. 1119-1122, 2006.

[20] J. Sumfleth, X. C. Adroher, and K. Schulte, "Synergistic effects in network formation and electrical properties of hybrid epoxy nanocomposites containing multi-wall carbon nanotubes and carbon black," Journal of Materials Science, vol. 44, no. 12, pp. 3241-3247, 2009. 

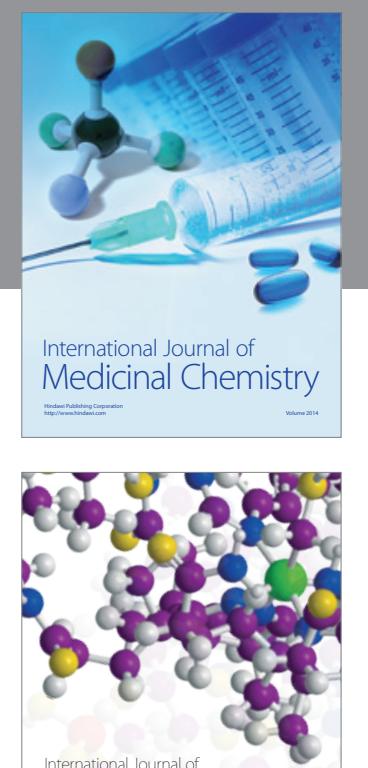

\section{Carbohydrate} Chemistry

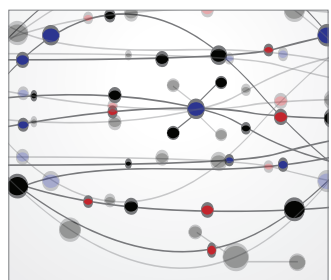

The Scientific World Journal
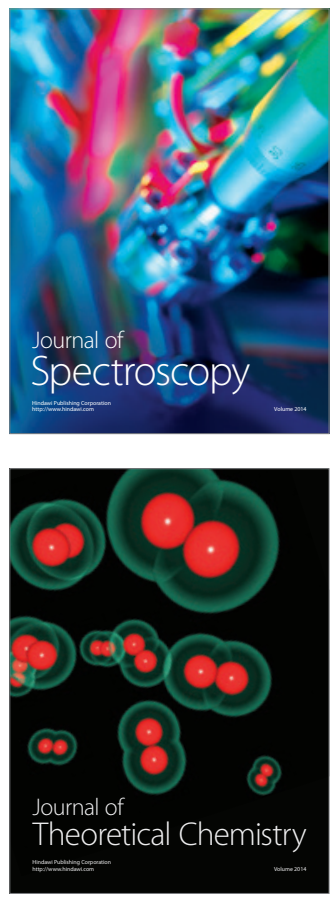
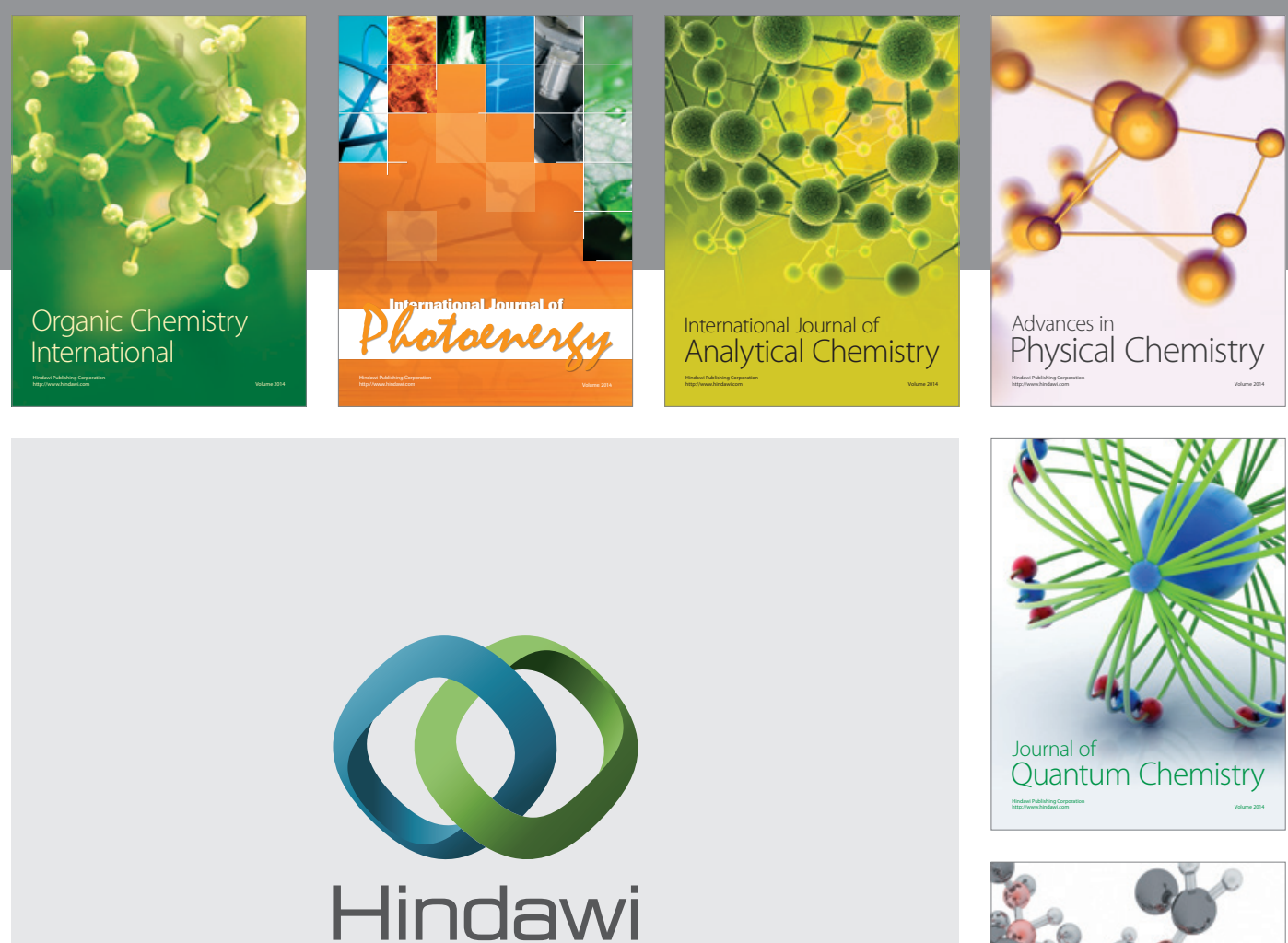

Submit your manuscripts at

http://www.hindawi.com

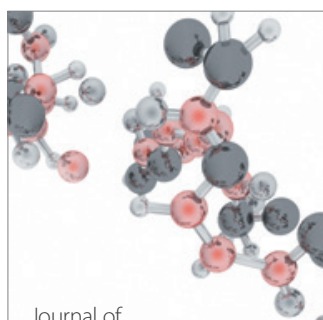

Analytical Methods

in Chemistry

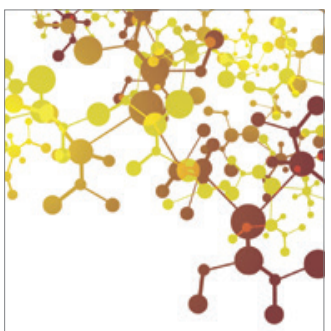

Journal of

Applied Chemistry

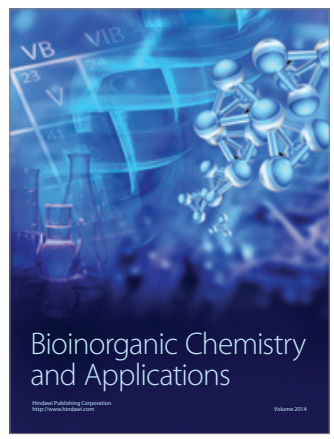

Inorganic Chemistry
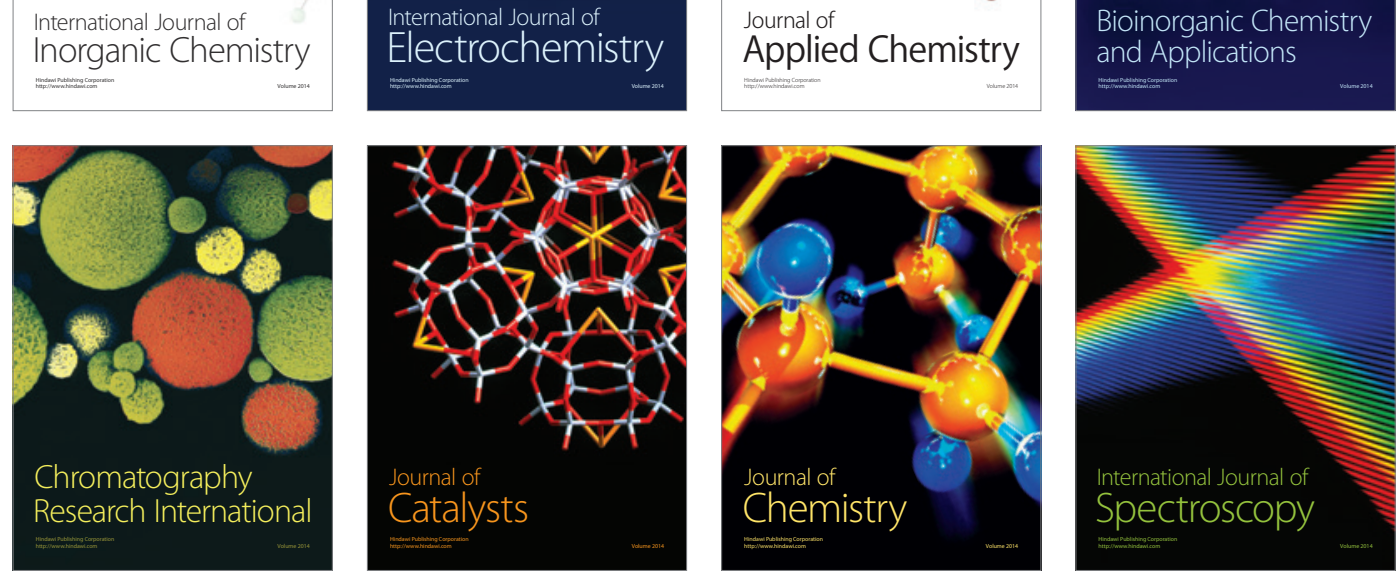